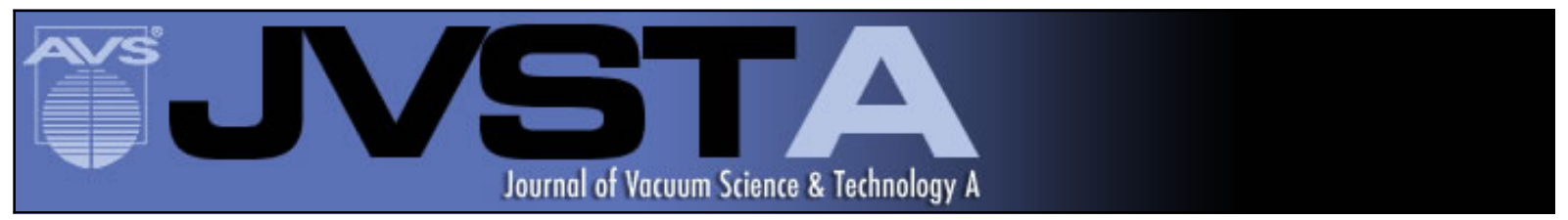

\title{
Surface analysis of gold containing polyimide films
}

D. G. Madeleine, S. A. Spillane, and L. T. Taylor

Citation: Journal of Vacuum Science \& Technology A 5, 347 (1987); doi: 10.1116/1.574158

View online: http://dx.doi.org/10.1116/1.574158

View Table of Contents: http://scitation.aip.org/content/avs/journal/jvsta/5/3?ver=pdfcov

Published by the AVS: Science \& Technology of Materials, Interfaces, and Processing

Articles you may be interested in

Evidence for surface plasmons in a liquid crystal containing gold nanoparticles

Appl. Phys. Lett. 101, 253103 (2012); 10.1063/1.4772066

Formation of gold nanoparticles embedded in a polyimide film for nanofloating gate memory Appl. Phys. Lett. 90, 123118 (2007); 10.1063/1.2716345

Surface microstructure analysis of cubic boron nitride films by transmission electron microscopy Appl. Phys. Lett. 88, 031904 (2006); 10.1063/1.2165288

Structure and optical properties of Au-polyimide nanocomposite films prepared by ion implantation Appl. Phys. Lett. 85, 5712 (2004); 10.1063/1.1829390

Electronic density of state in metal/polyimide Langmuir-Blodgett film interface and its temperature dependence J. Appl. Phys. 81, 1790 (1997); 10.1063/1.364035
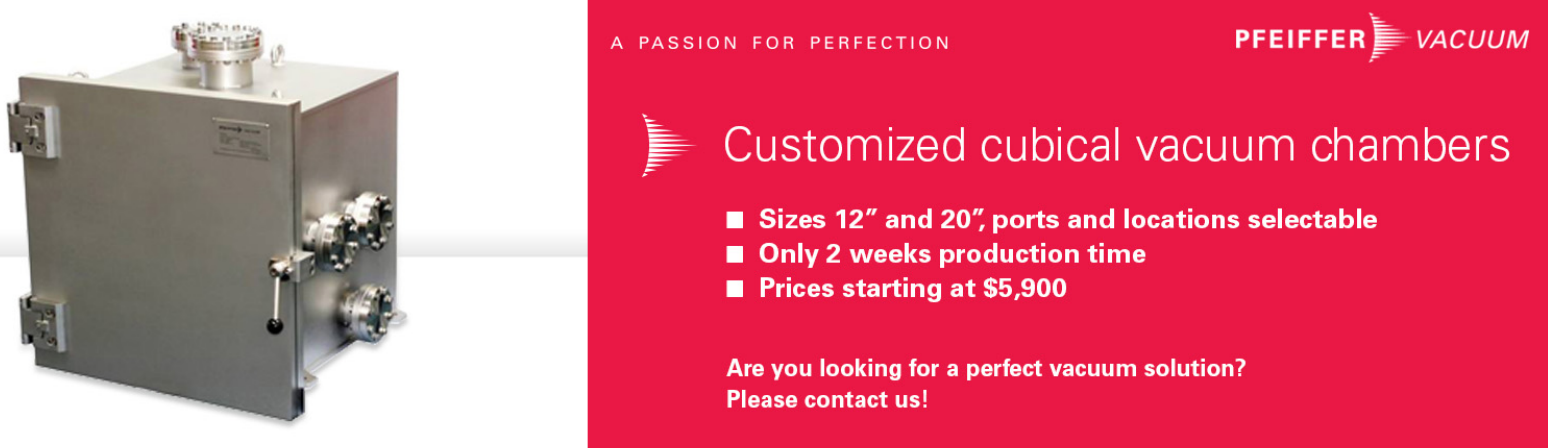


\title{
Surface analysis of gold containing polyimide films
}

\author{
D. G. Madeleine, S. A. Spillane, and L. T. Taylor \\ Department of Chemistry, Virginia Polytechnic Institute and State University, Blacksburg, \\ Virginia 24061-0699
}

(Received 7 July 1986; accepted 27 January 1987)

\begin{abstract}
Polyimide films with metallic surfaces were produced by thermal treatment of solutions containing $\mathrm{HAuCl}_{4} \cdot 3 \mathrm{H}_{2} \mathrm{O}$, hydrogen tetrachloroaurate trihydrate, and either Ciba-Geigy XU 218, poly [5(6)-amino-1-(4' phenyl)-1,3,3 trimethylindane-3,3',4,4'-benzophenonetetracarboxylimide] or BTDA-ODA, poly [ $p, p^{\prime}$-oxybis (phenylene) $-3,3^{\prime}, 4,4^{\prime}$-benzophenonetetracarboxylimide]. Scanning electron microscopy indicated that $0.1-\mu$ particles covered a large portion of the air side surface; whereas, $10-\mu$ particles covered the glass side surface of these films. Auger electron spectroscopy and x-ray photoelectron spectroscopy (XPS) indicated that the particles were gold in the metallic state. Model imide compounds were synthesized and used to evaluate the XPS spectra of both unmodified and gold containing films. Surface analysis data suggested that only a small amount of gold was located within the XPS sampling depth and that the observed gold particles resided underneath a polyimide overlayer. The discrete metal particles had an unexpected influence on the photoelectron spectra of the polyimide and the influence was dependent on particle size. A schematic model of the multilayered modified film surface was developed and the model further probed by electron flood gun and metal vapor deposition studies.
\end{abstract}

\section{INTRODUCTION}

The primary research effort in our laboratory has been directed towards the investigation of the structure-property relationships of polyimide films which have been modified by the incorporation of metal containing compounds. Ideally, these materials would retain the strength, flexibility, and thermal stability of the polyimide while exhibiting the enhanced electrical conductivity and reflectivity characteristic of the metal. These films are commonly synthesized by thermal imidization of a polyamic acid solution which contains a soluble metal salt. Alternatively, the metal may be added to a solution of a soluble polyimide and heated by the same thermal profile used during imidization. In some cases the resulting films usually have metal concentrated on the surface. In some cases this concentration of metal leads to enhanced conductivity and reflectivity. For instance, the incorporation of a palladium complex into a polyimide resulted in a metallic surface with a film surface conductivity increased ten orders of magnitude over that of an unmodified polyimide film. ${ }^{\prime}$ Reflective films exhibiting metal-oxide surfaces were also prepared from copper ${ }^{2}$ and $\operatorname{tin}^{3}$ additives which exhibited increased surface conductivity by five orders of magnitude. Other additives, such as gold ${ }^{4}$ and silver ${ }^{5}$ salts produced films with highly reflective surfaces, but no substantial increase in room-temperature conductivity was observed.

As a result of the interest by the microelectronics industry in the adhesion of metal to polymer surfaces, several articles have appeared in the literature which deal with the surface analysis of unmodified and metal-coated polyimide films. Leary and Campbell ${ }^{6}$ observed the nonstoichiometric nature of polyimide surfaces and identified a "partially oxidized" carbon component in the x-ray photoelectron spectroscopy (XPS) spectra of polyimides. By the study of model compounds, Buchwalter and Baise ${ }^{7}$ suggested that the "partially oxidized" carbon component arose from the phenyl ring carbons in the polyimide to which three or four carbonyl groups were attached. Calculation of core binding energies in model compounds by Silverman ${ }^{8}$ confirmed these assignments. One important conclusion of these authors is that the binding energy of phenyl ring carbons in imides and polyimides depends on the number of carbonyl groups attached to the phenyl rings. The binding energy is increased over that of the unsubstituted ring by $0.5 \mathrm{eV}$ for two carbonyl groups, ${ }^{8} 0.8$ $\mathrm{eV}$ for three carbonyl groups, ${ }^{9}$ and $1 \mathrm{eV}$ for four carbonyl groups. ${ }^{7}$ In addition, Ho and co-workers employed both XPS and ultraviolet photoelectron spectroscopy (UPS) to study the interaction of vapor deposited metals on polyimides and were able to identify specific interactions between the metal and organic substrate. ${ }^{10}$

In this present study, scanning electron microscopy (SEM), Auger electron spectroscopy (AES), and XPS were used to investigate the surface properties of model compounds, unmodified polyimide films and gold containing films prepared by the method outlined previously. The polyimides studied were Ciba-Geigy, XU 218,poly [5(6)-amino-1-( $4^{\prime}$ phenyl)-1,3,3 trimethylindane-3,3',4,4'- benzophenonetetracarboxylimide] and BTDA-ODA, poly [ $p, p^{\prime}$-oxybis (phenylene)-3,3',4,4'-benzophenonetetracarboxylimide], synthesized in our laboratory. The metal salt used was $\mathrm{HAuCl}_{4} \cdot 3 \mathrm{H}_{2} \mathrm{O}$, hydrogen tetrachloroaurate trihydrate.

\section{EXPERIMENT}

Three model imide compounds (Fig. 1) were prepared in our laboratory by the method of Dine-Hart and Wright. ${ }^{11}$ Model compound I was prepared by refluxing $0.02 \mathrm{~mol}$ of aniline with $0.01 \mathrm{~mol}$ of BTDA, 3,3',4,4'-benzophenonetetracarboxylic acid dianhydride, in $45 \mathrm{~g}$ of $N$-methylpyrollidone (NMP) for $2.5 \mathrm{~h}$ at $180^{\circ} \mathrm{C}$. The precipitate was recrys- 
<smiles>O=C(c1ccc2c(c1)C(=O)N(c1ccccc1)C2=O)c1ccc2c(c1)C(=O)N(c1ccccc1)C2=O</smiles>

$\mathrm{MCI}$<smiles>Cc1ccc(Oc2ccc(N3C(=O)c4ccccc4C3=O)cc2)cc1</smiles>

MC II

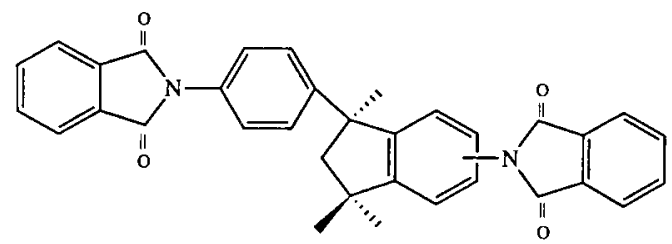

MC III

FIG. 1. Imide model compounds.

tallized from dimethylformamide (DMF). Model compound II was prepared by reacting $0.01 \mathrm{~mol}$ of $4,4^{\prime}$-bis(aminophenyl) ether and $0.02 \mathrm{~mol}$ of phthalic anhydride in the same manner as model compound I. The product was recrystallized from a mixture of $25 \% \mathrm{DMF}$ and $75 \%$ ethanol. Similarly, model compound III was formed by the reaction of $0.01 \mathrm{~mol}$ of DAPI, 5(6)-amino-1-(4'-aminophenyl)-1,3,3 trimethylindane, with $0.02 \mathrm{~mol}$ of phthalic anhydride. The product was precipitated in water, then recrystallized from a $10 \%$ water and $90 \%$ methanol mixture.

The structures of the polyimides which were studied are shown in Fig. 2. The method of film preparations was dictated by the polymer solubility. Both unmodified and modified versions of the soluble polyimide Ciba-Geigy XU 218 were made. The gold containing film was prepared by dissolving

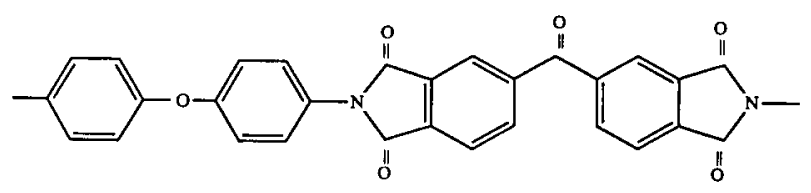

BTDA-ODA

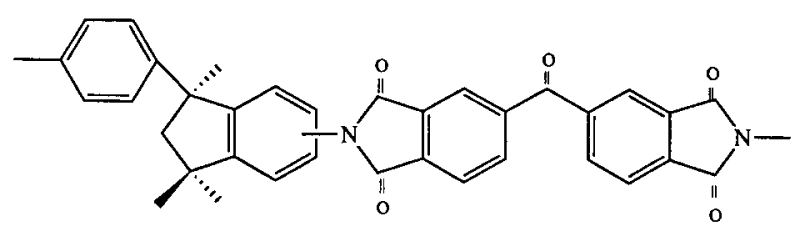

CIBA-GEIGY XU 218

FlG. 2. Polyimide structure of BTDA-ODA and Ciba-Geigy XU 218.
$0.004 \mathrm{~mol}$ of the polymer (with respect to the repeat unit) into $10 \mathrm{ml}$ of dimethylacetamide (DMAC) (Burdick and Jackson). After the polymer dissolved, $0.0015 \mathrm{~mol}$ of $\mathrm{HAuCl}_{4} \cdot 3 \mathrm{H}_{2} \mathrm{O}$ (Aldrich) was added with stirring. The solution was allowed to stir under a dry nitrogen atmosphere for $5 \mathrm{~h}$ and then was cast onto a glass plate with a doctor blade at a thickness of $0.4 \mathrm{~mm}$. The film was dried in a static air oven at $80^{\circ} \mathrm{C}$ for $0.5 \mathrm{~h}$, then placed in a forced air oven for $1 \mathrm{~h}$ each at 100,200 , and $300^{\circ} \mathrm{C}$. A similar procedure was used in the formation of films derived from the insoluble polyimide, but in this case starting with the monomers. Specifically, 4,4'-bis (aminophenyl)ether, ODA (Aldrich) was purified by recrystallization and sublimation prior to use. Monomer grade BTDA (Gulf) was heated to $200^{\circ} \mathrm{C}$ for $2 \mathrm{~h}$. The polyamic acid was formed by reacting $0.004 \mathrm{~mol}$ of the diamine and $0.004 \mathrm{~mol}$ of the dianhydride in $10 \mathrm{ml}$ of DMAC under a dry nitrogen atmosphere. Within $30 \mathrm{~min}$ the solution became viscous and $0.0015 \mathrm{~mol}$ of $\mathrm{HAuCl}_{4} \cdot 3 \mathrm{H}_{2} \mathrm{O}$ was added. The solution was cast on a glass plate and thermally imidized with the same temperature profile used in the synthesis of the soluble polyimide film modified with $\mathrm{HAuCl}_{4} \cdot 3 \mathrm{H}_{2} \mathrm{O}$. Throughout this paper the polymer surface in contact with the casting plate during the heating cycle will be referred to as the glass surface side; whereas, the surface in contact with the oven atmosphere is the air surface side.

XPS spectra were collected from a Perkin-Elmer Phi 530 $\mathrm{x}$-ray photoelectron spectrometer under high vacuum $\left(<5 \times 10^{-8}\right.$ Torr). A magnesium anode operating at $250 \mathrm{~W}$ was used in the production of achromatic $\mathrm{x}$ rays centered at $1253.6 \mathrm{eV}$. The model compounds were pressed onto indium foil prior to mounting on a piece of double-stick tape. No attempt was made to correct for charging by use of a flood gun, except as noted, and the binding energies cited have been referenced to the aromatic carbon signal at $285 \mathrm{eV}$. XPS data were acquired and stored by a Perkin-Elmer 7500 computer. Perkin-Elmer software was used in the curve fitting routine and calculation of the atomic concentration of elements present on the surface.

AES line scans were obtained by securing the film sample onto the probe with a conductive clip. The surface was sputtered with an argon ion etch prior to the line scan. Charging of the sample surface was minimized by using a beam voltage of $1200 \mathrm{~V}$ and a beam current of $5 \mathrm{nA}$. Electron micrographs were obtained with a Joel $35 \mathrm{C}$ scanning electron microscope.

\section{RESULTS AND DISCUSSION}

\section{A. Unmodified films and model compounds}

Good agreement between the expected distribution of carbon, nitrogen, and oxygen as obtained via classical elemental analysis and the atomic concentration as determined by XPS was found for model compounds (Table I). This demonstrates that the sensitivity factors used by the software in the calculation of atomic concentrations are reasonable, and that the surface concentration of the imide models is similar to the expected bulk stoichiometry. The values obtained for model compound I are also comparable to values previously obtained by others for the same compound. ${ }^{7}$

As mentioned previously, the $\mathrm{C} 1 s$ photoelectron spectra 
TABLE I. Relative elemental atomic and molecular group concentrations in model compounds (MC).

\begin{tabular}{|c|c|c|c|c|c|}
\hline & Oxygen & Nitrogen & Carbon & Carbonyl & Aromatic \\
\hline \multicolumn{6}{|l|}{ MC-I } \\
\hline Theor. & 13.9 & 5.6 & 80.6 & 17.2 & 82.8 \\
\hline Found: elemental analysis & $15.3(16.0)^{\mathrm{a}}$ & $5.6(4.9)$ & $79.1(79.2)$ & $\ldots$ & $\cdots$ \\
\hline Found: XPS & $13(14)$ & $6(5)$ & $81(81)$ & $13(16)$ & $87(84)$ \\
\hline \multicolumn{6}{|l|}{ MC-II } \\
\hline Theor. & 14.3 & 5.7 & 80 & 14.3 & 85.7 \\
\hline Found: elemental analysis & 14.5 & 5.6 & 80 & $\cdots$ & $\cdots$ \\
\hline Found: XPS & 16 & 6 & 78 & 11 & 89 \\
\hline \multicolumn{6}{|l|}{ MC-III } \\
\hline Theor. & 10 & 5 & 85 & 12.5 & 87.5 \\
\hline Found: elemental analysis & 9.8 & 5 & 85.2 & $\cdots$ & $\cdots$ \\
\hline Found: XPS & 10 & 5 & 85 & 9 & 91 \\
\hline
\end{tabular}

${ }^{a}$ Numbers in parentheses are from Ref. 7.

of imides and polyimides are quite complex owing to the difficulty in estimating the number of component peaks which comprise the spectrum. For instance, Silverman ${ }^{9}$ calculated and fitted the $\mathrm{C} 1 s$ spectrum of model compound I to five peaks, not including the shake-up signal. Added to the difficulty of curve fitting are variables such as peak position, intensity, width, and shape (degree of Gaussian versus Lorenzian). Due to the subjective manner of curve fitting, we fitted the C $1 s$ spectra in this report to only two peaks (Fig. 3 ) centered at the following energies: $288.8 \mathrm{eV}$ for the carbonyl carbons and $285.5 \mathrm{eV}$ for the remaining carbons. The peak centered at $292.2 \mathrm{eV}$ is due to the carbon shake up. Table I lists the percentage of carbonyl and aromatic carbon signal expected and found for the three model compounds. It should be noted that in all cases, the amount of carbonyl found is less and, subsequently, the amount of aromatic is more than expected.

Table II lists the elemental distribution of carbon, nitrogen, and oxygen as determined by XPS for unmodified polyimide films. It was found that the concentration of these elements is invariant as a function of take-off angle (TOA),

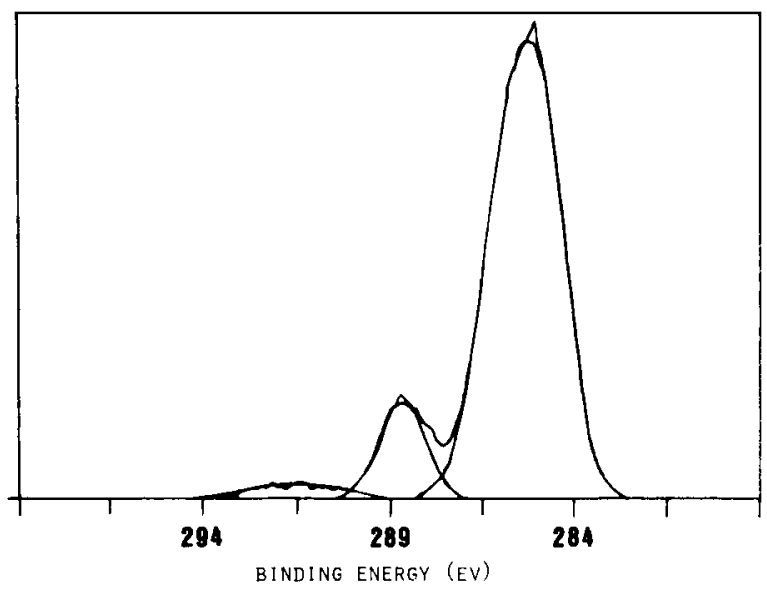

FIG. 3. Curve-fit C $1 s$ photoelectron spectrum of BTDA-ODA, which is typical of model compounds and unmodified films. which suggests that the polyimides investigated are elementally homogeneous within the sampling depth of XPS. However, the observed distribution of these elements was not always the same as the expected (theoretical) distribution. For example, it was found that the surface concentration of oxygen in the BTDA-ODA film was greater than the amount anticipated based on polymer stoichiometry. The surface enrichment of oxygen in the cured BTDA-ODA film could arise by several different mechanisms. First, it is possible that not all of the amic acid moieties in the polymer were converted to imide during thermal curing or that imide groups originally formed were hydrolyzed to amide and acid functionalities. It is also possible that water, adsorbed on the surface, is responsible for the excess oxygen content. However, the increased oxygen concentration was only observed in the BTDA-ODA film and not the XU 218 film. An explanation consistent with these results is based on the migration of the low molecular weight fraction of the polymer to the film surface. This process would enrich the surface of the BTDA-ODA film in end groups containing either anhydride or amine groups, the latter of which could be oxidized during the thermal cure of the film. In either case, the surface oxy-

TABLE II. Relative elemental atomic and molecular group concentrations of unmodified polyimide films from XPS analysis.

\begin{tabular}{|c|c|c|c|c|c|}
\hline & Oxygen & Nitrogen & Carbon & Carbonyl & Aromatic \\
\hline \multicolumn{6}{|c|}{ B'TDA-ODA } \\
\hline Theor. & 16.2 & 5.4 & 78.3 & 17.2 & 82.8 \\
\hline $\mathrm{TOA}=15^{\circ}$ & 19 & 4 & 77 & 11 & 89 \\
\hline$=30^{\circ}$ & 18 & 4 & 78 & 11 & 89 \\
\hline$=90^{\circ}$ & 19 & 4 & 77 & $11^{\mathrm{a}}$ & $89^{a}$ \\
\hline \multicolumn{6}{|l|}{ XU 218} \\
\hline Theor. & 11.9 & 4.8 & 83.3 & 14.3 & 85.7 \\
\hline $\mathrm{TOA}=15^{\circ}$ & 13 & 4 & 83 & 8 & 92 \\
\hline$=30^{\circ}$ & 11 & 5 & 84 & 8 & 92 \\
\hline$=90^{\circ}$ & 12 & 4 & 83 & 8 & 92 \\
\hline
\end{tabular}

${ }^{a}$ Values from Ref. 6 are carbonyl $=10.5,12.3$, and 10.6; and for aromatic $=89.5,87.7$, and 89.4 . 
gen content would increase. However, the commercial thermoplastic polyimide XU 218 is quite probably end capped with phthalic anhydride or a similar monofunctional unit. Migration of low molecular weight chains in this film would not lead to increased oxygen content, which is our experimentally observed result. As was the case with the model compounds, the $\mathrm{C} 1 s$ photoelectron spectra of the two unmodified polyimides were curve fitted and the areas corresponding to the carbonyl and the aromatic region were determined (Table II). The experimentally determined carbonyl carbon percentage for each film is much lower than the expected value. Similar but less dramatic results were also observed with the model compounds (Table I). The observation and extent of the reduced carbonyl signal is consistent with the investigation of commercially available and laboratory synthesized BTDA-ODA by Leary and Campbell. ${ }^{6}$ They concluded that side reactions, polymer fragments, trapped solvent, and paracrystalline formation could all be responsible for the carbonyl nonstoichiometry observed at the polymer surface.

\section{B. Modified films}

Scanning electron micrographs of the air side and glass side surface of the modified BTDA-ODA film are shown in Figs. 4(a) and 4(b). Similar surface features were also observed in the modified XU 218 film. The most striking feature of these films is the sharply defined aggregates approximately $10 \mu \mathrm{m}$ in diameter on the glass side surface and the

(a)

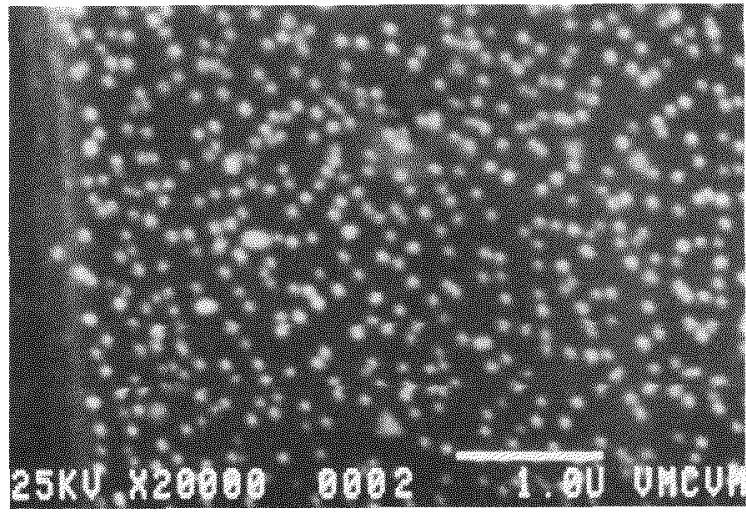

(b)

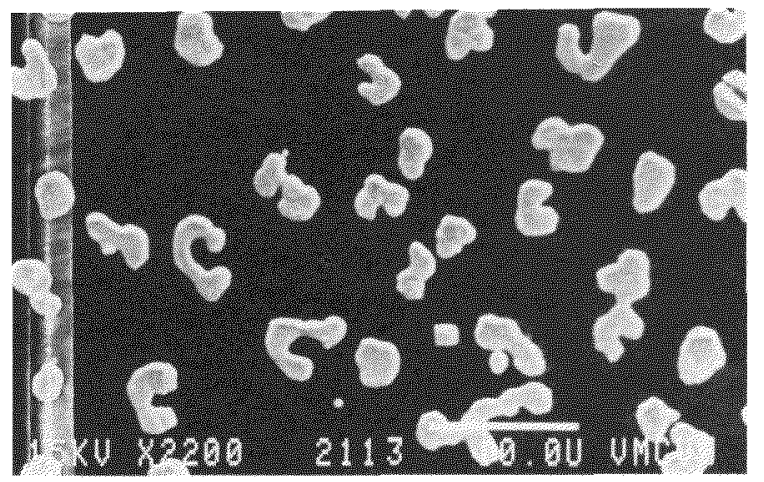

FIG. 4. Scanning electron micrograph of modified film surfaces: (a) air side surface at $22000 \times$; (b) glass side at $22000 \times$. diffusely defined smaller particles approximately $0.1 \mu \mathrm{m}$ in diameter on the air side surface. To more fully characterize the chemical nature of these aggregates an Auger line scan of the glass side surface was performed and is shown in Figs. 5(a) and 5(b). The Auger line scan measures the intensity of the gold Auger signal as a function of distance across the film surface. It was found that the gold signal went through a maximum as each aggregate was sampled. This experiment suggested that the particles are comprised of gold. Auger line scans for chlorine, oxygen, and carbon did not show maxima coincident with the aggregates, suggesting that the gold was in an uncombined state.

XPS results for the air side surface of the gold modified films are listed in Table III. As was the case for the unmodified films, the elemental distribution of polymer elements is homogeneous within the sampling depth of XPS. Further, the BTDA-ODA film has a surface oxygen content greater than that expected based on bulk polymer stoichiometry. As was the case with the model compounds and the unmodified films, the carbonyl content on the surface is significantly less than expected. The most surprising feature of these results is that gold was detected in very small quantities $(\sim 1 \%)$ even though the electron micrographs showed gold particles covering a much larger portion of the polymer surface. This suggests that the gold particles on the surface lie beneath a polyimide overlayer, which is slightly thinner than the XPS sampling depth.

A typical C $1 s$ spectrum of the air side surface of a modified polyimide film is quite similar to the spectrum shown in Fig. 3. Figure 6 shows the gold $4 f_{5 / 2,7 / 2}$ photopeaks at 88.7

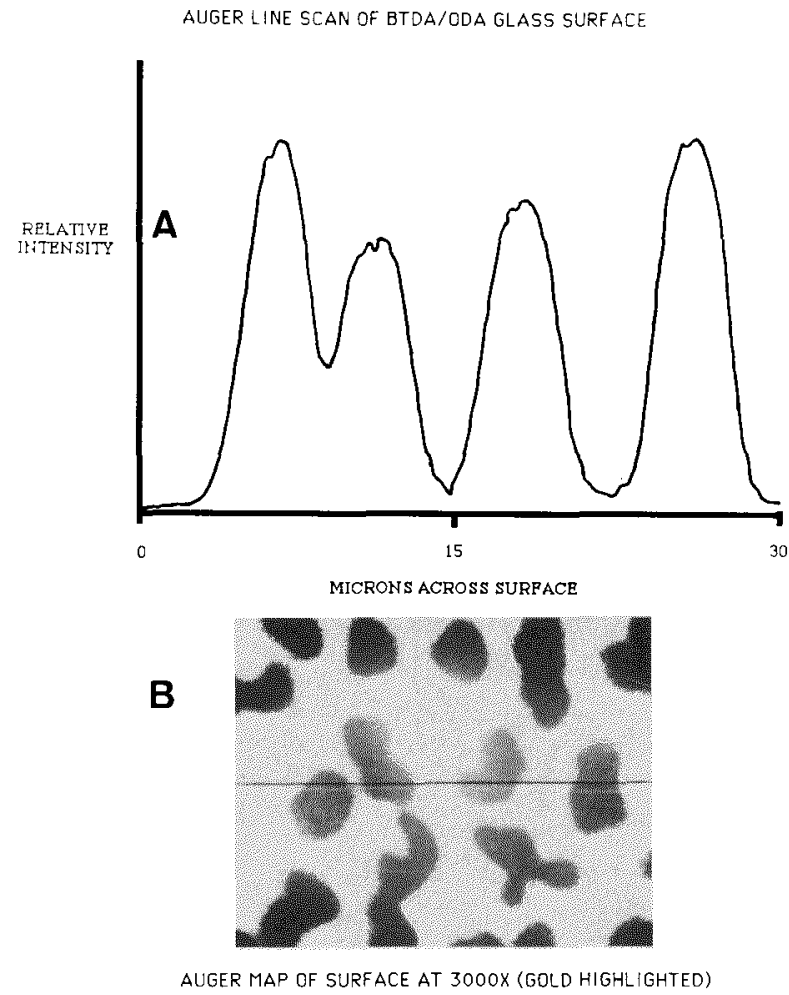

Fig. 5. Auger line scan modified film glass side: (a) Gold Auger signal intensity as a function of distance across film surface; (b) Auger electron map of glass side surface $(3000 \times)$ in the vicinity of line scan. Gold particles appear black and area of line scan depicted by line. 
TABLE III. Relative elemental atomic and molecular group concentrations of modified polyimide films from XPS analysis of the air side.

\begin{tabular}{|c|c|c|c|c|c|c|}
\hline & Gold & Oxygen & Nitrogen & Carbon & Carbonyl & Aromatic \\
\hline \multicolumn{7}{|c|}{ BTDA-ODA/Au } \\
\hline Theor. ${ }^{a}$ & $\cdots$ & 16.2 & 5.4 & 78 & 17.2 & 82.8 \\
\hline$=30^{\circ}$ & $0.4(0.5)$ & 20 & 4 & 75 & 8 & 92 \\
\hline$=90^{\circ}$ & $1.0(1.5)$ & 20 & 5 & 74 & 7 & 92 \\
\hline $\mathrm{TOA}=15^{\circ}$ & $1(0.1)^{b}$ & 14 & 4 & 83 & 6 & 94 \\
\hline$=30^{\circ}$ & $1(0.5)$ & 14 & 4 & 84 & 4 & 96 \\
\hline$=90^{\circ}$ & $1(2.0)$ & 14 & 4 & 83 & 3 & 97 \\
\hline
\end{tabular}

${ }^{a}$ Elemental percentages calculated for polymer alone.

${ }^{\mathrm{b}}$ Numbers in parentheses are concentrations measured for the glass side.

and $85.1 \mathrm{eV}$. The value typically reported for the $4 f_{7 / 2}$ metallic gold photopeak is $83.8 \mathrm{eV},{ }^{12}$ which indicates that the gold on the air side is shifted $1.3 \mathrm{eV}$ to higher binding energy. If gold exists as the uncombined metal, the question of why the gold photopeak is shifted becomes pertinent.

The preceding results suggest that few gold particles are located within the XPS sampling depth; and that surface is almost exclusively comprised of polyimide. Only the much larger sampling depth of SEM reveals the numerous gold particles near the surface. The discontinuity of the surface gold particles within the insulative polyimide matrix provides no mechanism for charge neutralization during the XPS experiment. Hence, the metallic gold particles charge and give rise to a higher binding energy on the air side surface than the value expected for elemental gold. Consequently, the $1.3-\mathrm{eV}$ shift in the gold photopeaks is probably due to a physical effect and not a chemical effect.

The distribution of gold within the XPS sampling depth was examined by variable take-off angle XPS (Table III). While the amount of gold detected was small, it increased with increasing depth regardless of the side of the BTDAODA film as well as on the glass side surface of the XU 218 film. This suggests that these outermost film surfaces are

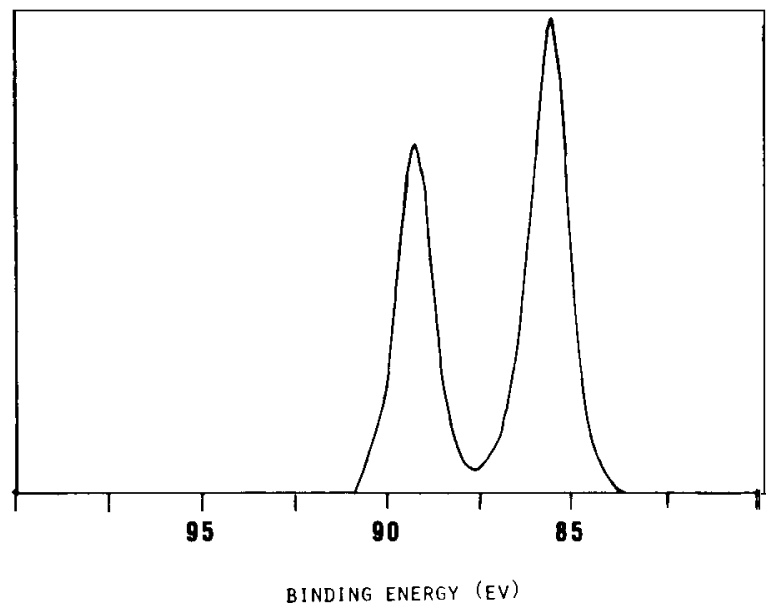

FIG. 6. Au $4 f_{5 / 2,7 / 2}$ photoelectron spectrum of air side surface of modified film. virtually all polyimide which decreases in concentration as sampling depth increases. No such effect was observed on the air side surface of the XU 218 film which indicate a homogeneous distribution of gold throughout the XPS sampling depth. Taken together these data suggest that the outermost layer of both surfaces of the films studied is comprised almost totally of polyimide. Beneath this polymer overlayer lies gold particles; large on the glass side and small on the air side. The presence of this overlayer is responsible for the "adhesion" of the metal to the film and provides a barrier to mechanical abrasion of the gold from the film.

A typical $\mathrm{C} 1 \mathrm{~s}$ spectrum of the glass side surface of either film is shown in Fig. 7 which is much different than the spectrum characteristic of the air side surface (Fig. 3). Due to difficulties in sample charging, vide infra, the polymer elemental concentrations could not be accurately quantified. The glass side $\mathrm{C} 1 s$ spectrum was pairwise fitted into two distinct polyimide signals (i.e., carbonyl and aromatic carbon). The difference in binding energy (within a set) between the carbonyl and aromatic photopeaks is the same binding energy difference observed in unmodified films. The two sets of $\mathrm{C} 1 \mathrm{~s}$ photopeaks are believed to be due to differential polyimide charging. A double set of peaks was also observed in the nitrogen and oxygen XPS signals. It is interest-

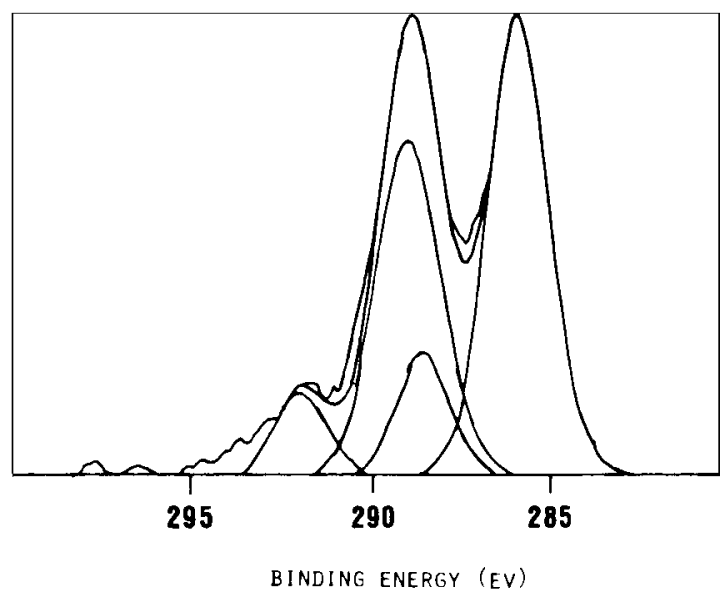

FIG. 7. C $1 s$ spectrum of glass side surface of a modified film. 
ing to note, however, that only one set of $4_{5 / 2,7 / 2}$ photopeaks was seen for gold on the glass side surface.

These distorted XPS spectra were investigated further and these data provide additional information concerning the glass side surface structure. The double photopeaks associated with the polymer may be a result of the process by which the large gold particles form and grow on the glass side surface of the film during thermal cure. This growth process is currently being studied in our laboratory. It is thought that the gold salt is homogeneously distributed throughout the bulk of the film prior to high-temperature thermal treatment $\left(>200^{\circ} \mathrm{C}\right.$ ). During the $200^{\circ} \mathrm{C}$ isotherm the dispersed metal diffuses to nucleation sites on the glass side surface of the film. Migration of metal to these growing centers results in zones of metal depletion around the large particles. Indeed, these depletion zones can be seen as halos around the large particles when the film is observed with transmitted light optical microscopy..$^{13}$ Therefore, two distinct regions of the polymer matrix are formed; the depletion zones and the regions which still contain metal dispersed in the polymer matrix. A schematic diagram of these films is shown in Fig. 8. It is believed that these two regions give rise to the double set of photopeaks observed in the photoelectron spectra of the polymer glass side surface. The lower binding energy photopeaks may result from photoelectrons ejected from the depletion zones. The higher binding energy photopeaks arise from the polymer matrix which still has gold dispersed in it. Upon x-ray excitation the dispersed metal assumes a positive charge relative to the surrounding polymer matrix. The net effect of this dispersed positive charge is to retard the escape of photoelectrons from this region, which manifests itself as a second photoelectron peak at higher binding energy. Therefore, the double set of photopeaks associated with the polymer on the glass side surface of the film is a result of segregation of the metal into zones which contain distinctly different amounts of metal. The air side surfaces of these films do not contain the large particles and segregation of the metal does not occur. Therefore, only one set of photopeaks is observed on the air side surface and photoelectron spectra typical of an unmodified film are observed.

The charging observed on the glass side surface was investigated further by evaporating a small amount of gold onto the polymer surface. The photopeaks of the glass side appeared unchanged from that of the uncoated sample except for one important difference; two sets of gold peaks were now observed. This result would only occur if the gold deposited on the surface is at a different potential than the dispersed "native" gold particles. The two gold signals may come about as a result of the fact that the evaporated gold is electrically isolated from the native gold by the polymer overlayer. This result substantiates the model of a definite polymer overlayer on the glass side surface. It was also noted that the difference in binding energy between the two curvefit gold signals is $2.6 \mathrm{eV}$, which is exactly equal to the difference in binding energy between the two sets of polyimide signals recorded in the $\mathrm{C} 1 s$ spectrum of Fig. 7. That both sets of gold and polyimide photopeaks are offset by the same potential suggests that the depletion zones and the deposited gold are at one potential; while, the polyimide with the dispersed gold is separated by a $2.6-\mathrm{eV}$ potential. These observations lend credence to the suggetion that the two sets of signals characteristic of the glass side surface arise from the distribution of gold in the insulative polymer matrix.

It was then suggested that if the double signal observed in Fig. 7 was a result of differential charging between the depletion zones and the polymer containing dispersed gold; then, charge neutralization by means of an electron flood gun may influence the observed spectrum. As our XPS was not equipped with a flood gun the samples were analyzed on a spectrometer which had this option. However, this older spectrometer had lower resolution so that the identical sample produced somewhat different spectra [Fig. 7 vs. Fig. 9 (a) ]. In any case, application of the flood gun produced two changes in the XPS spectrum of the glass side surface. First, the entire spectrum moved to lower binding energy due to charge neutralization by the electron gun. Second and most important, the two peaks observed in the charged spectrum (Fig. 7) collapsed into one broad photopeak upon neutralization as is depicted in Fig. 9(b). This result would be expected if the electrons provided by the flood gun moderated the potential difference between the different regions of polyimide at the surface.

In conclusion, we have produced flexible polyimide films with metallic gold surfaces by the incorporation of $\mathrm{HACl}_{4} \cdot 3 \mathrm{H}_{2} \mathrm{O}$ into solutions of polyimide or polyamic acid.

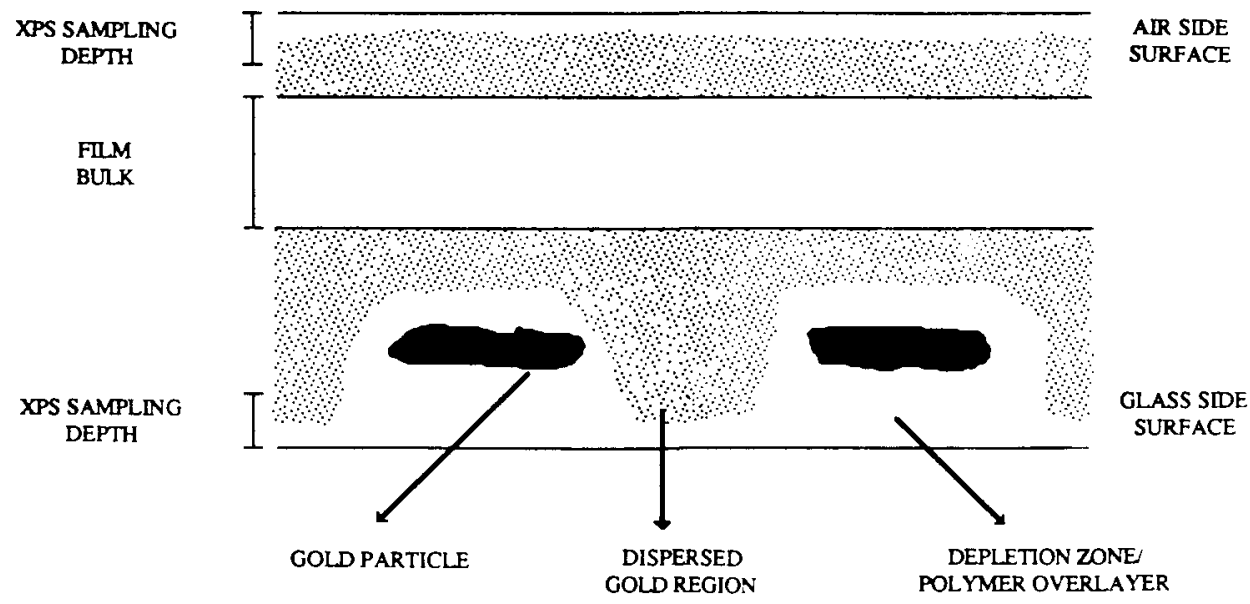

FIG. 8. Cross-section representation of gold distribution in modified films. 


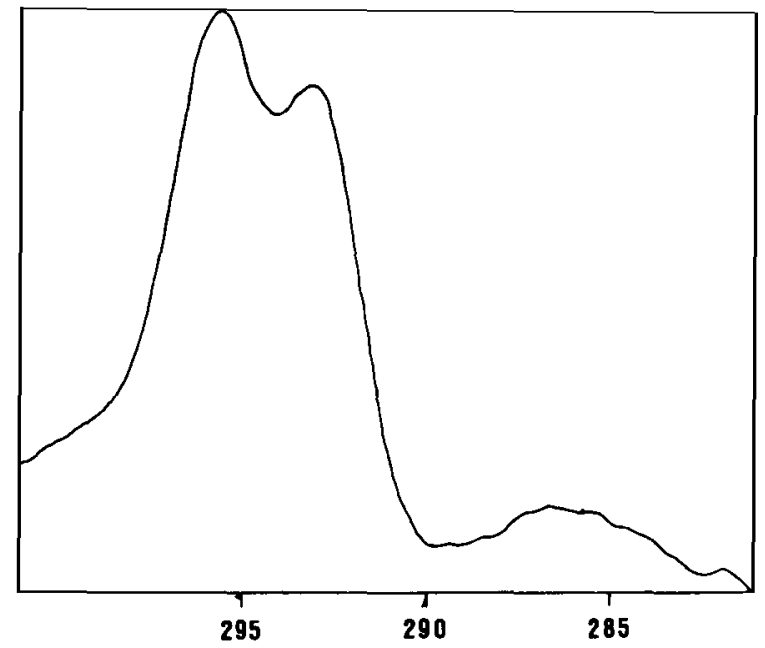

(a) BINDING ENERGY (EV)

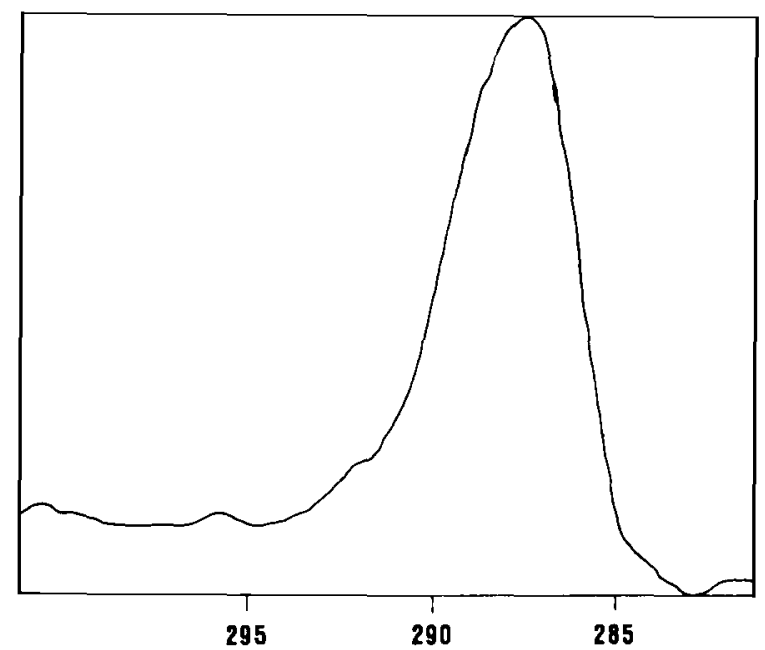

(b)

BINDING ENERGY (EV)

FIG. 9. XPS spectra of modified film-glass side surface: (a) before electron fiood gun neutralization; (b) after neutralization.
This modification does not cause a significant chemical change in the surface of the films as determined by XPS. The gold particles which comprise the metallic surface lie just beneath a polyimide overlayer and are approximately $100 \times$ larger on the glass side than the air side surface. This overlayer provides a barrier to mechanical abrasion of the gold on the film surface. The complicated XPS spectra of the glass side appears to correlate with the known structure of the surface.

\section{ACKNOWLEDGMENTS}

The authors gratefully acknowledge the financial support of the National Aeronautics and Space Administration. The expertise and patience of Frank Cromer in assisting with many of the surface analyses are appreciated.

'T. L. Wohlford, J. Schaff, L. T. Taylor, A. K. St. Clair, T. A. Furtsch, and E. Khor, in Conductive Polymers, edited by R. B. Seymour (Plenum, New York, 1981).

${ }^{2}$ S. A. Ezzell, T. A. Furtsch, E. Khor, and L. T. Taylor, J. Polym. Sci. Polym. Chem. Ed. 21, 865 (1983).

${ }^{3}$ S. A. Ezzell and L. T. Taylor, Macromol. 17, 1627 (1984).

${ }^{4}$ D. G. Madeleine and L. T. Taylor, in Polyimides: Synthesis, Characterization and Application, edited by K. L. Mittal (Plenum, New York, 1985), Vol. 2, p. 670 .

${ }^{5}$ R. K. Boggess and L. T. Taylor, in Ref. 4, p. 691.

${ }^{6}$ H. J. Leary and D. S. Campbell, Surf. Interface Analysis 1, 75 (1979).

${ }^{7}$ P. L. Buchwalter and A. I. Baise, in Polyimides: Synthesis, Characterization and Application, edited by K. L. Mittal (Plenum, New York, 1985), Vol. 1, p. 537.

${ }^{8}$ B. D. Silverman, P. N. Sanda, P. S. Ho, and A. R. Rossi, J. Polym. Sci. Polym. Chem. Ed. 23, 2857 (1985).

${ }^{9}$ B. D. Silverman, P. N. Sanda, J. W. Bartha, P. S. Ho, and A. R. Rossi, in Ref. 4 , p. 511.

${ }^{10}$ P. S. Ho, P. O. Hahn, J. W. Bartha, G. W. Rubloff, F. K. LeGoues, and B. D. Silverman, J. Vac. Sci. Technol. A 3, 739 (1985).

${ }^{11}$ R. A. Dine-Hart and W. W. Wright, Makromol. Chem. 143, 189 (1971). ${ }^{12}$ C. D. Wagner, W. M. Riggs, L. E. Davis, and J. F. Moulder, Handbook of Photoelectron Spectroscopy, edited by G. E. Muilenberg (Perkin-Elmer Co., Eden Prairie, MN, 1979).

${ }^{13}$ D. G. Madeleine, L. T. Taylor, and T. C. Ward, Polym. Prep. Am. Chem. Soc. Div. Polym. Chem. 28, 1 (1987). 